\title{
O Design do filme: o processo criativo da cenografia no cinema maranhense
}

\author{
Melissa Almeida Silva ${ }^{1}$; \\ Bruno Serviliano Santos Farias;
}

resumo:

Esse artigo aponta afinidades entre design e cinema mediante o trabalho do diretor de arte, que tem a função de traduzir as ideias do diretor por meio da composição da imagem cinematográfica, estabelecendo assim, diálogos com o espectador por meio da linguagem não verbal. O objetivo foi apresentar, através de um estudo de caso, o processo criativo da direção de arte, com foco na cenografia, do curta-metragem maranhense Um desvio para o vermelho, aprovado no Edital SECMA, ainda na sua fase de pré-produção e escrito pela cineasta Rose Panet. Ao final do artigo foi apresentado as imagens da proposta final desenvolvidas em software 3D.

palavras-chave:

direção de arte; cinema; cenografia

Espaço reservado para organização do congresso.

\footnotetext{
${ }^{1}$ http://lattes.cnpq.br/1155454400928895

${ }^{2}$ http://lattes.cnpq.br/4483482439913996
} 


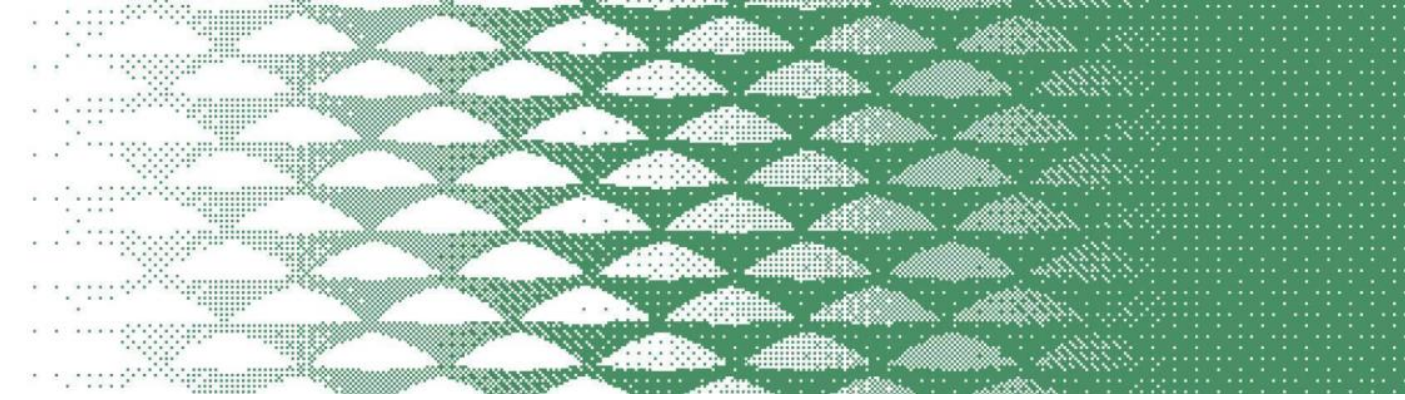

\section{Introdução}

O cinema possui uma linguagem multifacetada, composta por signos visuais e sonoros de naturezas distintas. Se expressando tanto pelo som, quanto pela imagem, a sétima arte se aproxima estreitamente do design, campo que abrange a comunicação visual. Vera Bungarten afirma que desenhar um filme é uma atividade do design, onde a "elaboração dos signos visuais na construção da imagem cinematográfica está inserida no escopo teórico do Design, considerando a forma abrangente como esta área de conhecimento se apresenta neste momento contemporâneo." (2013, pág. 194). Para a autora, desenhar um filme consiste em construir imagens que traduzam a ideia geral da obra cinematográfica apresentada primeiramente na forma verbal, sendo escrita (roteiro) e oral (diálogos entre o diretor e a equipe).

A direção de arte é uma especialidade onde o design apresenta uma das suas raízes mais profundas no campo do cinema. Essa área é responsável pela concepção da cenografia, composição do figurino e maquiagem, apresentando papel indispensável na imagem final e na ideia central da obra. Nesse estudo, abordaremos a direção de arte com foco na cenografia, que comporta todo o espaço, móveis e objetos dispostos em cena.

Refletindo sobre a importância do diretor artístico para a construção do sentido na imagem cinematográfica e a importância do design para o cinema, torna-se primordial entender as particularidades dessa atividade, abordando como diretores de arte norteiam seus processos de tradução da imagem verbal (roteiro) para a imagem construída (representação). O objetivo desse artigo é apresentar, por meio de um estudo de caso, o processo criativo da direção de arte, com foco na cenografia, do curta-metragem maranhense Um desvio para o vermelho, aprovado no Edital SECMA, ainda na sua fase de pré-produção e escrito pela cineasta Rose Panet. Para guiar a pesquisa e as contribuições para o campo, o estudo aborda o papel da cenografia na linguagem cinematográfica, e, de forma resumida, aspectos importantes da história do cinema maranhense.

\section{O papel da cenografia na linguagem cinematográfica}

\subsection{Direção de arte e Design de Produção}

O cinema é resultado de um trabalho conjunto de diversos profissionais que exercem funções diferentes entre si, mas que buscam o mesmo objetivo: transmitir a ideia geral, oriunda do roteiro, por meio de imagem e som. Entre eles, podemos destacar o diretor, o diretor de fotografia e o designer de produção. BUNGARTEN (2013, pág. 102) afirma que esses três citados formam o tripé da imagem cinematográfica e os chama de designers da imagem.

Em algumas pesquisas encontradas, foi possível perceber a mudança da nomenclatura de Direção de Arte para Design de Produção, tornando relevante compreender a diferença entre os dois termos. Bungarten (2013, p.104) explica que a direção de arte compõe o espaço fílmico, ou seja, define tudo que será colocado diante da câmera: projeta os ambientes, define a paleta de cores, texturas e formas do cenário, figurino e maquiagem. Em outras palavras, determina toda a estética da obra. Expandindo o papel da direção de arte para além dessas funções, em 1939, William C. Menzies participou da produção de $E$ o vento levou e afirmou que juntamente com criação de toda a estética fílmica, participou também do storyboards, contribuindo com o diretor David O. Selznick ao especificar enquadramentos e movimentos de câmera.

Com tantas visões e modificações surgiu um novo termo production designer, como David passou a chamar Menzies (Lobrutto 2002, p.02). Mauro Baptista (2005) apresenta uma hipótese sobre essa transição, e segundo o autor a mudança se deve à chegada de novas tecnologias de finalização de imagens realizadas na pós-produção.

A imagem 1 faz referência ao estudo de Vera Bungarten (2013) destacando o escopo do presente estudo: cenário, mobiliário e objetos em cena. 


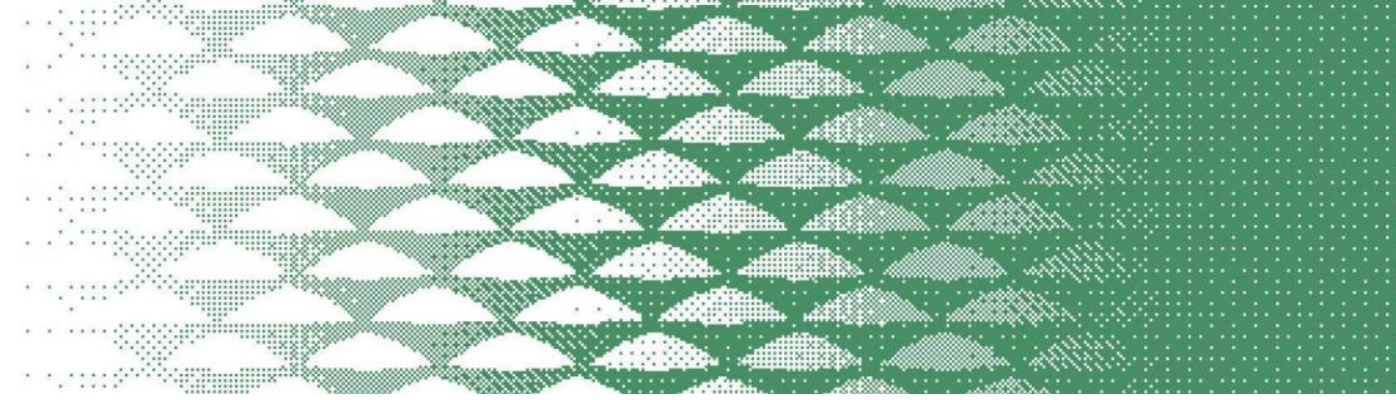

procurando conceitos a partir de um estudo aprofundado para resolver problemas, se assemelha muito à linha de pensamento do cenógrafo (o que neste artigo chamamos de diretor de arte). Seguindo as considerações de Silva e Sá (2008), nesse estudo não se pretende sugerir que o diretor de arte e o designer são uma única profissão. Nessa reflexão, o design não deve ser considerado como uma profissão, mas sim o seu sentido mais legítimo: o de projetar. O autor segue afirmando que

(...) mesmo com suas especificidades, a Cenografia tem o mesmo approach projetual do amplo campo do Design, dialogando profundamente com questões mais específicas do design visual, design de produtos ou do design de interiores. (SILVA E SÁ, 2008, p. 97).

\section{O cinema maranhense}

A história do cinema do Maranhão começa poucos meses depois da projeção de L'Arrivée d'un train à La Ciotat, primeiro filme do mundo, exibido em 1895. É marcada pelos chamados exibidores ambulantes, projecionistas que viajavam de cidade em cidade com os mais variados tipos de projetores exibindo filmes em espaços públicos. Com a capacidade de registar e criar películas, os aparelhos de projeção acabaram por incentivar a produção local, e em 1902 o Bioscópio criou os primeiros registros em terras maranhenses, com imagens exibidas na noite de comemoração da Adesão do Maranhão (ARAUJO, 2017). Depois disso, o cinema local se limitou a documentários de fatos históricos, se mostrando um pouco tímida em relação à produção cinematográfica brasileira, o que se percebia nos jornais locais, que limitavam suas notícias a produções do resto do país e do mundo. Até a década de 60, ainda não existiam obras de ficção e os filmes produzidos no estado traduziam-se apenas em imagens de paisagem, e a maioria dos documentários eram produzidos por outros estados, contratados por políticos ou empresas com a finalidade de propaganda.

É só a partir dos anos 70 que a produção local se inicia com mais independência. Embora o regime militar estivesse em vigor, surgiram grupos artísticos, a exemplo do Coral Universitário, fundado pela Universidade Federal do Maranhão. Élida Sousa (2013) afirma que o sucesso do coral fomentou Mário Cella ${ }^{4}$ a fazer novos grupos: de teatro, folclore e cinema (2013, pág. 32). Surge então o Laborarte (Laboratório de expressões artísticas) e o Cineclube Universitário, com o intuito de incentivar os estudantes à cinematografia maranhense. Em 1975 o formato Super- $8^{5}$ se tornou popular em todo o país, por ser de fácil manuseio e de baixo custo em relação às bitolas profissionais de cinema ( $35 \mathrm{~mm}$ e $16 \mathrm{~mm})$. Aconteceu então a $1^{\text {a }}$ Jornada Maranhense de Super-8, e durante o período de premiação Os Pregoeiros de São Luís, do cineasta maranhense Murilo Santos, se destacou no III Festival de Cinema - FENACA, e foi nessa ocasião que o formato super- 8 se popularizou de fato no Maranhão, proporcionando oficinas de cinema e o reconhecimento do potencial do estado (SILVA, 2017).

Atualmente, no cinema maranhense o gênero em destaque é a ficção, contudo, segundo Andréia Silva (2017), parte das produções são abandonadas por conta da complexidade e as envolvem, como contratar profissionais de diferentes áreas (atores, fotógrafos, diretores de arte, etc.). Em contrapartida, a criação da primeira escola de cinema do Maranhão em 2015 e os festivais que acontecem periodicamente em São Luís, como o Festival Guarnicê de Cinema (antiga Jornada Maranhense Super8), o Maranhão na Tela e o Festival Internacional Lume de Cinema incentivam o surgimento de novos cineastas e novas produções, ao mesmo tempo que favorece cada vez mais o surgimento de espectadores e amantes da arte. Outro incentivo à arte é o Edital SECMA de Projetos Audiovisuais do Maranhão, resultado de uma parceria entre a Secretaria de Estado da Cultura (Secma) e a Agência Nacional do

\footnotetext{
4 Professor aposentado da UFMA e fundador do primeiro Cineclube do Maranhão.

5 Formato cinematográfico desenvolvido em 1960 lançado pela Kodak.
} 


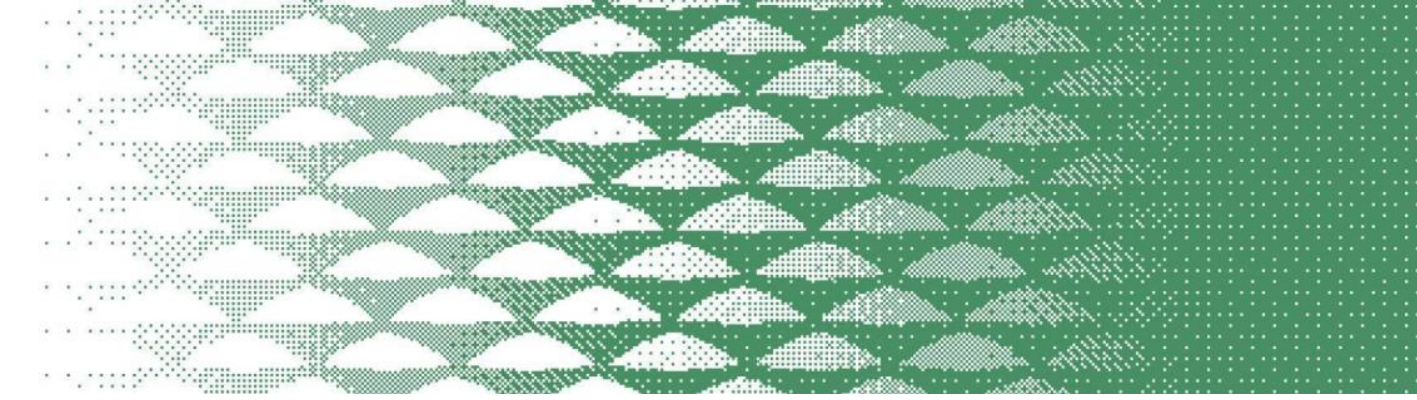

Cinema (Ancine) por meio do Fundo Setorial do Audiovisual (FSA), no qual o curta Um desvio para o vermelho, abordado nesse estudo, foi submetido e aprovado.

\section{Um desvio para o vermelho - uma proposta de cenografia}

Em janeiro de 2020 recebi o convite para fazer a direção de arte do curta-metragem maranhense Um desvio para o vermelho, escrito e futuramente dirigido pela cineasta Rose Panet, primeira mulher a dirigir um longa-metragem de documentário no estado. O projeto foi aprovado no $7^{\circ}$ Edital SECMA de Projetos Audiovisuais do Maranhão. A chamada pública é fruto de uma parceria entre a Secretaria de Estado da Cultura (Secma) e a Agência Nacional do Cinema (Ancine), por meio do Fundo Setorial do Audiovisual (FSA). O edital selecionou 16 projetos na categoria curta-metragem. A pré-produção do curta se encontra em fase inicial e o roteiro está em processo de mudança, o que certamente implicará em adaptações futuras na direção de arte. Contudo, uma vez que artigo objetiva esmiuçar o processo de design no fazer da direção de arte, a mudança posterior do roteiro não irá influenciar nesse processo.

\subsection{Sobre o curta}

O curta nos apresenta parte da vida de Verônica, uma mulher de 25 anos que está vivendo uma dupla crise, com sua ascendência/origem e com o seu namorado, por quem nutre um amor profundo, mas confuso por causa de suas diferenças ideológicas. Trabalha como corretora de imóveis, mora só e é obcecada pela cor vermelha, mas tem medo de sangue e passa mal quando vê e quando faz exame de sangue. Quase todas as peças do seu guarda roupa são vermelhas. Seu apartamento tem paredes, móveis e objetos vermelhos em excesso. Tem uma preferência por alimentos vermelhos e é vegetariana. Sua obsessão também é política. Engajada, de esquerda e feminista, ela se pergunta o que tudo isso realmente significa na sua vida. Verônica se acha muito diferente de seus pais e decide fazer um teste de DNA. Até a chegada do exame, veremos o quotidiano de sua vida, sua relação com a sociedade, com os pais e com o namorado.

O curta será ambientado nos dias atuais na cidade de São Luís, onde $40 \%$ dele será filmado no interior do apartamento de Verônica, e $60 \%$ em outros locais da cidade. A proposta de cenografia vai se limitar ao apartamento da protagonista, mais especificamente na sala de estar. A escolha se deu pela quantidade de cenas filmadas nesse ambiente.

\subsection{Metodologia}

Marcelo Santos (2017) caracteriza as diferentes atribuições de uma produção cinematográfica (roteiro, direção de arte, direção de fotografia, montagem, atuação, trilha sonora, etc.) como subsistemas, e Morin (2005) define um subsistema como “(...) todo sistema que manifeste subordinação em relação a um sistema no qual ele é integrado como parte” (MORIN, 2005, pág. 175). O processo de concepção da cenografia seguirá as etapas discutidas por Marcelo Santos (ibid. pág. 25), que são baseadas nos conceitos de Jorge Vieira (2008) sobre propostas evolutivas ontológicas, que auxiliam na compreensão dos processos de abertura e fechamento de cada subsistema, no caso do presente estudo, as etapas de concepção da cenografia. As etapas são: rompimento, preparação, expansão, transição, maturação e clímax. No artigo serão apresentadas apenas as três primeiras, uma vez que as restantes se encaixam na fase de produção e pós-produção. 
Film Design: the creative process of scenography in the cinema of Maranhão.

Abstract: This article points out affinities between design and cinema through the work of the art director, who has the function of translating the director's ideias through the composition of the cinematographic image, building dialogues with the viewer through non-verbal language. The purpose was to present through a case study, the creative process of art direction, focusing on scenography, of the short film from Maranhão Um desvio para o vermelho, approved in the SECMA edital, still in the preproduction stage and written by filmmaker Rose Panet. At the end of the article, the final imagens developed in 3D software of the final proposal were presented.

Keywords: art direction, cinema, scenography.

\section{Referências bibliográficas}

BAPTISTA, Mauro. Design e cinema: caminhos possíveis de pesquisa, in: Estudos em Design: 2007

A Direção de Arte no Cinema: uma abordagem sistêmica sobre seu processo de criação, in: Revista Digital do LAV. Santa Maria: 2017.

BARTHES, Roland. O óbvio e o obtuso, Nova Fronteira. Rio de Janeiro: 1990

BUNGARTEN, Vera. A imagem cinematográfica: convergência entre Design e Cinema. Tese de Doutorado - Departamento de Artes e Design, Pontifícia Universidade Católica do Rio de Janeiro. Rio de Janeiro: 2013.

COELHO, Luiz Antonio. 0 papel narrativo do objeto cênico, in: $7^{\circ}$ Congresso de Pesquisa \& Desenvolvimento em Design. Curitiba: 2006.

LAUFHUTTE, Maria Luiza Zenobio. Design de produção no cinema: o processo de comunicação visual da cenografia. Dissertação de Mestrado - Departamento de Artes e Design, Pontifícia Universidade Católica do Rio de Janeiro. Rio de Janeiro: 2018.

LO BRUTTO, Vincent. The filmmaker's guide to production design. New York: Allworth Press. Nova York: 2002.

MORIN, Edgar. 0 Método 2: a vida da vida, Editora Sulina. Porto Alegre: 2005.

SOUSA, Élida Maria. Ciné - $\mathbf{O}$ pulsar coletivo dos cineclubes em São Luís. Tese (Bacharel em Jornalismo). Faculdade Estácio de São Luís. São Luís: 2013. 